\title{
Carcaças e componentes não-carcaça de cordeiros terminados em pasto de azevém recebendo suplementação concentrada
}

\author{
Carcasses and non carcasses components of lambs on Italian ryegrass receiving concentrate \\ supplementation \\ Ticiany Maria Dias Ribeiro ${ }^{\mathrm{I} *}$ Ciniro Costa ${ }^{\mathrm{I}}$ Alda Lúcia Gomes Monteiro ${ }^{\mathrm{II}}$ \\ Hugo von Linsingen Piazzetta" Maria Angela Machado Fernandes" ${ }^{\text {II }}$ Odilei Rogerio Prado ${ }^{\mathrm{II}}$
}

\section{RESUMO}

O trabalho foi desenvolvido com o objetivo de avaliar a resposta das características objetivas e subjetivas das carcaças e dos não componentes da carcaça de cordeiros desmamados precocemente e terminados em pasto de azevém anual ao fornecimento crescente de suplemento concentrado (sem suplementação; 0,9\%; 1,8\% do peso corporal e ad libitum) na dieta. Os cordeiros foram abatidos ao atingirem $32 \mathrm{~kg}$ de peso corporal e medidas corporais foram tomadas antes do abate. Após o abate, registraram-se os pesos da carcaça quente, do conteúdo digestivo e dos não-componentes da carcaça. As carcaças permaneceram por 24 horas em câmara fria $a 5^{\circ} \mathrm{C}$, obtendo-se o peso da carcaça fria. Obtiveram-se os rendimentos $e$ as medidas objetivas e subjetivas das carcaças e, por cálculos, as compacidades de perna e carcaça. Os dados foram submetidos às análises de regressão e de correlação simples. A suplementação concentrada apresentou efeito linear positivo $(P<0,05)$ sobre pesos e rendimentos de carcaça quente e fria, compacidade de perna e de carcaça, estado de engorduramento $e$ conformação das carcaças. A oferta crescente de suplementação concentrada aos cordeiros jovens desmamados e terminados em pasto de azevém promoveu a obtenção de carcaças maiores e com rendimento superior, com melhor conformação e estado de engorduramento, podendo resultar em melhores oportunidades de comercialização e de preços pagos ao produtor.

Palavras-chave: estado de engorduramento, peso de carcaça, rendimento de carcaça, vísceras.

\section{ABSTRACT}

The study was performed to evaluate the subjective and objective measurements of the carcasses and non-carcasses components of weaned lambs grazing on Italian ryegrass pasture fed with different levels of concentrate supplementation (without supplementation, $0,9 \%, 1,8 \%$ of body weight and ad libitum). Lambs were slaughtered at $32 \mathrm{~kg}$ of live weight. After slaughtering, hot carcass, digestive content and weight of noncarcass components were recorded. Weight of cold carcasses was assessed after the refrigeration for $24 \mathrm{~h}$ at $5^{\circ} \mathrm{C}$. Weight, yield and carcasses measurements were taken and then the leg and carcass compactness were calculated. Data were subjected to regression and simple correlation analysis. The concentrate supplementation levels had a positive linear effect on the weights and yields of hot and cold carcass and leg and carcasses compactness. Supplementation of weaned lambs grazing on annual ryegrass enabled to get carcasses of better conformation and fat covering. These effects may result in better price opportunities and marketing for farmers.

Key words: carcass yield, carcass weight, fat covering, viscera.

\section{INTRODUÇÃO}

A ovinocultura de corte tem despertado interesse como forma de aproveitamento dos recursos naturais na produção de proteína de qualidade. Entretanto, para que possa competir com a comercialização de outras espécies, o produtor deve disponibilizar ao mercado carne proveniente de animais jovens, que possuam carcaças de qualidade superior (BROCHIER \& CARVALHO, 2009). O cordeiro, quando comparado aos ovinos adultos, apresenta maior eficiência de ganho de peso e melhor qualidade de carcaça, principalmente nos primeiros seis meses de

IUniversidade Estadual Paulista (UNESP), Programa de Pós-graduação em Zootecnia, CP 560, 18618-970, Botucatu, São Paulo, Brasil. E-mail: ticiany.ribeiro@gmail.com. *Autor para correspondência.

"IUniversidade Federal do Paraná (UFPR), Curitiba, PR, Brasil. 
vida, e essas características podem ser otimizadas pelo uso de sistemas adequados de alimentação.

Tradicionalmente, a base da alimentação dos ovinos é a pastagem natural, com nível tecnológico limitado, o que torna difícil a obtenção de resultados produtivos (CARVALHO et al., 2007). A suplementação concentrada é ferramenta que permite a produção de carne ovina de forma mais intensiva, principalmente quando se trata de pequenas e médias propriedades, em que as áreas disponíveis de pastagem são limitadas (CARVALHO et al., 2006).

Resultados favoráveis na suplementação concentrada de cordeiros terminados em pasto, quanto ao desempenho e às características da carcaça, têm sido relatados (GARCIA et al., 2003; BORTON et al., 2005). Porém, seria interessante conhecer o ponto ótimo de fornecimento de suplemento, considerando a resposta em qualidade do produto final e a viabilidade econômica dos sistemas de suplementação, quando da decisão pela adoção da técnica, para que não haja desperdício no uso dos recursos.

Dentro desse contexto, o trabalho teve como objetivo avaliar a utilização de níveis de suplementação concentrada ( $0 \% ; 0,9 \% ; 1,8 \%$ do peso corporal e ad libitum) sobre a carcaça e os não componentes da carcaça de cordeiros desmamados aos 42 dias de idade e terminados em azevém anual (Lolium multiflorum Lam.).

\section{MATERIAL E MÉTODOS}

O experimento foi conduzido entre Agosto de 2005 e Janeiro de 2006 no Laboratório de Produção e Pesquisa em Ovinos e Caprinos (LAPOC/UFPR), em Pinhais-PR, na Área de Preservação Ambiental do Irai, a $25^{\circ} 25^{\prime}$ Sul e $49^{\circ} 8^{\prime}$ Oeste e $915 \mathrm{~m}$ acima do nível do mar.

Foram utilizados 48 cordeiros desmamados do grupo genético Suffolk, não castrados, mantidos em pastagem de azevém anual (Lolium multiflorum Lam.), sobressemeado em pasto perene de Tifton-85 (Cynodon sp), sob os tratamentos: (1) sem suplementação; (2) suplementados com ração concentrada a $0,9 \%$ do peso corporal (PC) em matéria seca; (3) suplementados em $1,8 \%$ do PC em matéria seca e (4) suplementados ad libitum. Para estimar o consumo de suplemento no tratamento ad libitum, contabilizou-se a quantidade média de ração concentrada consumida, considerando o ajuste diário da dieta, procurando manter $10 \%$ de sobra no comedouro. A partir da quantidade média de ração consumida nos períodos entre as pesagens dos cordeiros e peso corporal médio destes no mesmo período, obteve-se o percentual consumido de matéria seca em relação ao peso corporal, que foi estimado em 3,2\% em matéria seca.

Após o nascimento, os cordeiros foram pesados, identificados e permaneceram em aprisco suspenso de piso ripado, com suas mães. Os animais foram desmamados precocemente aos 42 dias de idade, everminados e adaptados à cerca elétrica e ao ambiente da pastagem da área experimental duas semanas antes do início das avaliações. O período experimental teve início quando os cordeiros desmamados apresentavam média de 60 dias de idade e 18,45kg PC.

O delineamento experimental foi de blocos ao acaso, com quatro tratamentos e três repetições (piquetes). Os animais foram distribuídos uniformemente nos tratamentos segundo o peso ao nascer, o sexo e o tipo de parto (simples ou gemelar). Foram abatidos dois cordeiros machos por repetição, totalizando seis cordeiros por tratamento.

A pastagem de azevém, colhida a cada 14 dias por meio da simulação de pastejo, apresentou os valores nutricionais médios: $18,61 \%$ de proteína bruta (PB); 25,29\% de fibra de detergente ácido (FDA); 52,58\% de fibra de detergente neutro (FDN) e 2,44Mcal kg-1 de energia metabolizável (EM).

A suplementação concentrada era ração farelada composta de milho moído (51\%), farelo de soja (31\%), farelo de trigo (15\%), calcário calcítico (0,5\%), sal comum (2\%) e núcleo mineral (0,5\%), seguindo recomendações do NRC (1985) para ganhos de $200 \mathrm{~g}$ dia $^{-1}$. Esse concentrado apresentou teores médios de 20\% PB; 2,98Mcal kg ${ }^{-1}$ EM; 21,34\% FDN e 6,31\% FDA. Para minimizar a interferência do fornecimento sobre o comportamento ingestivo dos animais, este era realizado duas vezes ao dia, às $08 \mathrm{~h}$ e $16 \mathrm{~h}$. O ajuste da quantidade de concentrado era efetuado a cada 14 dias após pesagem dos animais. Durante todo o período, os cordeiros tiveram livre acesso à suplementação, água e suplemento mineral.

O método de utilização da pastagem foi o de lotação contínua com carga animal variável. Os cordeiros-teste permaneceram nos piquetes durante todo o período de avaliação até o abate, enquanto os reguladores foram usados para adequar a carga animal pela técnica put and take (MOTT \& LUCAS, 1952). Buscou-se manter a altura média da pastagem em $15 \mathrm{~cm}$, de acordo com CARVALHO et al. (2001).

Os cordeiros foram abatidos ao atingirem o peso individual de $32 \mathrm{~kg}$, após jejum sólido de aproximadamente 16 horas. Antes do abate, foi registrado o peso vivo ao abate (PVA, peso após o jejum) e realizaram-se as medidas biométricas. Os animais foram mantidos em pé sobre superfície plana para essas medidas, segundo metodologia de OSÓRIO \& OSÓRIO (2003). Utilizando fita métrica, foram feitas as seguintes mensurações in vivo: comprimento corporal; altura do anterior; altura do posterior; e perímetro torácico.

Ao abate, foi realizada a insensibilização dos cordeiros por eletronarcose com descarga elétrica de 
220V por oito segundos, sangria, esfola e evisceração. Os subprodutos foram pesados: o conjunto pelego mais patas e cabeça; sangue; vísceras vermelhas (coração, pulmão, baço, fígado e rins); aparelho urinário mais testículos; gordura perirenal; gordura mesentérica e gordura omental. O trato digestório foi esvaziado e pesado para o peso do conteúdo gastrintestinal e cálculo do peso de corpo vazio (PVA - conteúdo gastrintestinal). Avaliou-se o rendimento verdadeiro (RV) que é a relação entre peso da carcaça quente (PCQ) e o peso de corpo vazio (PCV) (RV\%=PCQ/PCV*100). Após evisceração, obteve-se o peso de carcaça quente e calculou-se o rendimento por RCQ\%=PCQ/PVA*100.

Após lavagem com água, as carcaças foram penduradas pelas articulações tarso-metatarsianas em ganchos com abertura de $17 \mathrm{~cm}$. Foram avaliadas visualmente quanto à conformação, de acordo com OSÓRIO \& OSÓRIO (2003), atribuindo-se valores de um a cinco, segundo a distribuição dos seus planos musculares. As carcaças foram avaliadas quanto ao estado de engorduramento, pela distribuição harmônica da gordura, e pontuadas de um a cinco, de extremamente magra até extremamente gorda (OSÓRIO \&OSÓRIO, 2003).

Foi avaliada a morfometria das carcaças, segundo GARCIA et al. (2003): comprimento da perna, comprimento interno da carcaça, largura da garupa, perímetro da garupa, largura do tórax e profundidade do tórax. Por meio de cálculo, obteve-se o índice de compacidade da carcaça (relação entre o peso da carcaça fria e comprimento interno da carcaça) e índice de compacidade de perna (relação entre largura da garupa e comprimento de perna).

Após as medições, as carcaças foram resfriadas em câmara fria a $5^{\circ} \mathrm{C}$ por 24 horas. Pesou-se a carcaça, registrando-se o peso de carcaça fria (PCF). Obteve-se, por cálculo, o rendimento da carcaça fria ou comercial (RCF\%=PCF/PVA*100) e a perda de peso ao resfriamento (PPR\%=(PCQ-PCF/PCQ)*100).

A análise estatística foi realizada com auxílio do programa estatístico SAEG versão 9.1 (2007). As variáveis dependentes foram submetidas à análise de regressão simples, considerando componentes lineares, quadráticos e cúbicos, segundo o nível de suplementação, a 5\% de probabilidade, pelo PROC REG. Parte das variáveis (medidas biométricas, medidas da carcaça, idade de abate dos cordeiros) foi submetida à análise de correlação simples de Pearson, obtida pelo PROC CORR, a 5\%.

\section{RESULTADOS E DISCUSSÃO}

A suplementação concentrada não teve efeito sobre variáveis biométricas dos cordeiros, que apresentaram, em média, 65,96cm de comprimento corporal; 62,38cm de altura de anterior e 61,75cm de altura de posterior, confirmando que essas medidas são influenciadas principalmente pelo genótipo dos animais.
Conforme as equações apresentadas na tabela 1, houve resposta linear negativa do perímetro torácico in vivo $(\mathrm{Y}=82,09-2,37 \mathrm{X})$ aos níveis de suplementação; para cada unidade percentual adicional no nível de suplementação, houve redução de $2,37 \mathrm{~cm}$ no perímetro torácico in vivo. Houve correlação significativa e positiva entre perímetro torácico in vivo e idade ao abate $(\mathrm{r}=0,67 ; \mathrm{P}<0,05)$ dos cordeiros. Cordeiros não suplementados foram abatidos com idade superior (198 dias; $\mathrm{P}<0,01$; idade de abate =186,6-25,83X; $\mathrm{R}^{2}=0,92$ ) a dos cordeiros com suplementação ad libitum (107 dias), o que provavelmente refletiu em maior desenvolvimento do perímetro torácico, conforme LANDIM et al. (2007) obtiveram para cordeiros de diferentes genótipos. Resultados semelhantes foram observados por YÁÑEZ et al. (2004) com cabritos.

Foi observado aumento linear no peso do corpo vazio em função do nível de suplementação $\left(\mathrm{R}^{2}=0,87 ; \mathrm{Y}=24,11+1,84 \mathrm{X}\right)$. O peso de conteúdo gastrintestinal dos cordeiros terminados com dieta exclusivamente em pasto foi maior em relação aos suplementados, devido ao maior tempo de permanência dos alimentos volumosos (pasto) em concordância com GESUALDI JR. et al. (2001) e maior enchimento do trato gastrintestinal dos animais submetidos a dietas com maiores proporções volumoso:concentrado (FERREIRA et al., 2000). CARVALHO et al. (2005) obtiveram redução no peso do conteúdo gastrintestinal com o aumento da suplementação concentrada (0 a 2,5\% do PC) para cordeiros em pasto de Tifton-85. Para cada unidade percentual a mais de suplementação, houve acréscimo de $1,84 \mathrm{~kg}$ no peso de corpo vazio e redução de $0,94 \mathrm{~kg}$ no peso do conteúdo gastrintestinal. Segundo WHETSEL et al. (2004), alimentos volumosos apresentam menor densidade energética quando comparados a alimentos concentrados, o que leva à maior necessidade de ingestão, podendo justificar o maior volume de ingesta no momento do abate. Do ponto de vista comercial, menor proporção de conteúdo gastrintestinal pode gerar maior rendimento de porções comestíveis, disponível para a comercialização (CARVALHO et al., 2005).

Quanto ao intestino delgado, foi observado aumento linear de peso $\left(\mathrm{R}^{2}=0,59\right)$ à medida que aumentaram os níveis de suplementação. A mesma resposta foi observada por MEDEIROS et al. (2008) com ovinos Morada Nova, para os quais, à medida que se elevou a quantidade de concentrado na dieta, houve aumento do peso e do comprimento do intestino, como forma de ampliar a área de digestão e absorção de nutrientes. DROUILLARD et al. (1991) verificaram que os pesos dos intestinos são reduzidos em resposta ao fornecimento restrito de proteína e energia, fato que 
Tabela 1 - Equações de regressão, coeficientes de determinação $\left(\mathrm{R}^{2}\right)$ e valores de probabilidade para características da carcaça e não componentes da carcaça de cordeiros desmamados em pasto de azevém, submetidos a níveis crescentes de suplementação concentrada.

\begin{tabular}{|c|c|c|c|}
\hline Variáveis & Equação & $\mathrm{R}^{2}$ & $\mathrm{p}$ \\
\hline \multicolumn{4}{|l|}{ Características da carcaça } \\
\hline Comprimento de perna (cm) & $Y=41,08-1,20 X$ & 0,57 & 0,011 \\
\hline Perímetro de garupa (cm) & $Y=59,4+1,30 X$ & 0,59 & 0,009 \\
\hline Peso do corpo vazio (kg) & $Y=24,11+1,84 X$ & 0,87 & 0,0011 \\
\hline Peso de carcaça quente $(\mathrm{kg})$ & $\mathrm{Y}=12,02+1,24 \mathrm{X}$ & 0,89 & 0,000 \\
\hline Peso de carcaça fria (kg) & $Y=11,71+1,19 X$ & 0,89 & 0,000 \\
\hline Rendimento de carcaça quente (\%) & $Y=38,70+2,69 X$ & 0,83 & 0,000 \\
\hline Rendimento de carcaça fria (\%) & $Y=37,68+2,62 X$ & 0,85 & 0,000 \\
\hline Índice de compacidade de perna & $Y=0,53+0,03 X$ & 0,79 & 0,0067 \\
\hline Índice de compacidade de carcaça $\left(\mathrm{kg} \mathrm{cm}^{-1}\right)$ & $\mathrm{Y}=0,22+0,03 \mathrm{X}$ & 0,92 & 0,0004 \\
\hline Conformação de carcaça (visual, 1-5) & $Y=1,53+0,60 X$ & 0,86 & 0,0049 \\
\hline Estado de engorduramento (visual, 1-5) & $Y=1,47+0,71 X$ & 0,84 & 0,0036 \\
\hline \multicolumn{4}{|l|}{ Não-componentes da carcaça } \\
\hline Pelego com cabeça e patas (kg) & $Y=5,25+0,48 X$ & 0,78 & 0,0003 \\
\hline Intestino delgado (kg) & $\mathrm{Y}=0,68+0,14 \mathrm{X}$ & 0,59 & 0,009 \\
\hline Conteúdo digestivo $(\mathrm{kg})$ & $Y=6,94-0,95 X$ & 0,84 & 0,0002 \\
\hline Vísceras vermelhas (kg) & $\mathrm{Y}=1,38+0,11 \mathrm{X}$ & 0,70 & 0,002 \\
\hline Gordura mesentérica (kg) & $Y=0,21+0,04 X$ & 0,50 & 0,023 \\
\hline Gordura omental (kg) & $\mathrm{Y}=0,07+0,03 \mathrm{X}$ & 0,59 & 0,009 \\
\hline
\end{tabular}

$\mathrm{R}^{2}=$ coeficiente de determinação.

foi confirmado nesse trabalho para cordeiros sem suplementação que tiveram menor quantidade de proteína (18\%) em sua dieta em pastagem.

A suplementação de cordeiros desmamados terminados em pasto promoveu aumento linear nos pesos e rendimentos de carcaça quente e fria, conforme as equações de regressão apresentadas na tabela 1. Essas equações permitem visualizar que é possível obter carcaças mais pesadas e com maiores rendimentos com maior nível de suplementação em pasto para essa categoria. A cada unidade percentual adicional na suplementação, houve aumento de $1,24 \mathrm{~kg}$ no peso de carcaça quente; $1,19 \mathrm{~kg}$ no peso de carcaça fria; 2,69\% no rendimento de carcaça quente e 2,62\% no rendimento de carcaça fria. Era esperado que esses rendimentos melhorassem com o aumento da suplementação concentrada devido à menor proporção de conteúdo digestivo nos cordeiros no momento do abate, já relatado. CARVALHO et al. (2006) e DANTAS et al. (2008), trabalhando com cordeiros da raça Santa Inês em pastagem nativa enriquecida com capim buffel, sem suplementação e suplementados com concentrado em $1 \%$ e $1,5 \%$ PC, observaram que o aumento na suplementação concentrada, em regime de pastejo, proporcionou aumento linear dos pesos ao abate e de carcaça. BARROS (2008) analisou a viabilidade econômica dessa suplementação concentrada na terminação dos cordeiros em pastagem de azevém. Para tal, considerou propriedade com 150 matrizes localizada na região metropolitana de Curitiba, $\mathrm{PR}$, com ciclo anual de produção e custos de produção, remuneração de mão de obra e preços pagos ao produtor da mesma Região. A suplementação ad libitum, com consumo estimado de ração igual a 3,2\% do PC, apresentou melhor lucratividade, pois, apesar de os cordeiros consumirem maior quantidade média de ração (881g dia-1 $)$, o tempo de terminação foi menor do que para os que consumiam 1,8\% do PC (redução de 25 dias para cada unidade percentual de suplementação) e com pesos e rendimentos superiores de carcaça. No entanto, recomenda-se que, na decisão pela adoção de suplementação ad libitum pelos produtores, seja conhecida a viabilidade econômica de cada situação.

Assim como para as medidas in vivo, algumas medidas realizadas nas carcaças - comprimento interno $(50,55 \mathrm{~cm})$ e externo da carcaça $(57,68 \mathrm{~cm})$, largura da garupa $(22,97 \mathrm{~cm})$, largura de tórax $(22,96 \mathrm{~cm})$ e profundidade do tórax $(25,41 \mathrm{~cm})$ - não apresentaram resposta $(\mathrm{P}>0,05)$ aos níveis de suplementação. A literatura é conflitante em relação a essas respostas: SOUZA et al. (2010) obtiveram aumento das medidas das carcaças com cordeiros desmamados Santa Inês em pasto de Tifton-85 entre 0 a $2 \%$ PC dia ${ }^{-1}$. DANTAS et al. (2008), com cordeiros Santa Inês, não verificaram 
efeito de inclusão de suplementação concentrada sobre medidas das carcaças.

Houve relação linear negativa entre comprimento de perna (CP) e níveis de suplementação ( $\left.\mathrm{R}^{2}=0,57\right)$, conforme a equação $\mathrm{CP}=41,08-1,20 \mathrm{X}$ (Tabela 1), e, como consequência, houve aumento linear no índice de compacidade da perna (ICP=0,53+0,03X; $\mathrm{R}^{2}=0,92 ; \mathrm{ICP}=$ largura da garupa sobre comprimento da perna), já que a largura da garupa não sofreu efeito do aumento de suplementação. O perímetro de garupa também aumentou conforme a suplementação ( $\left.Y=59,4+1,30 X ; R^{2}=0,59\right)$.

Apesar da suplementação não ter influenciado o comprimento interno das carcaças, apresentou efeito positivo sobre o peso de carcaça fria, o que resultou em aumento linear na compacidade da carcaça dos cordeiros ( $\mathrm{Y}=0,22+0,03 \mathrm{X} ; \mathrm{R}^{2}=0,92$ ). Com o conjunto de respostas apresentadas na tabela 1 , verifica-se que foi possível a obtenção de carcaças mais compactas, com pernas também mais compactas, quando se ofertou suplemento concentrado aos cordeiros Suffolk, assim como foi obtido por MEDEIROS et al. (2008) quando suplementou cordeiros Morada Nova em pasto. Esses resultados também corroboram os de BUENO et al. (2000) que observaram maior compacidade das carcaças de cordeiros Suffolk abatidos em diferentes idades com o aumento de peso das carcaças quente e fria.

Tanto a conformação $\left(\mathrm{R}^{2}=0,86\right)$ quanto o estado de engorduramento $\left(R^{2}=0,84\right)$ das carcaças responderam positivamente à suplementação, indicando melhor qualidade das carcaças de animais jovens e desmamados precocemente quando esses recebem dieta de maior densidade energética, na terminação em pastagem, mesmo que esta apresente boa qualidade (18\% PB). A maior concentração energética na dieta também levou à maior quantidade de gorduras mesentérica e omental. Foi observada correlação positiva entre a gordura de cobertura da carcaça e gordura mesentérica $(\mathrm{r}=0,77 ; \mathrm{P}<0,05)$. No caso da gordura perirenal, a resposta à suplementação não foi obtida, contrariando parcialmente a literatura, que frequentemente relata respostas positivas (GARCIA et al., 2003; HOMEM JR. et al., 2010).

\section{CONCLUSÃO}

Carcaças maiores e de rendimento superior podem ser obtidas em cordeiros jovens desmamados precocemente e terminados em pasto com o fornecimento da suplementação concentrada após o desmame. Essa suplementação favorece também a obtenção de carcaças de cordeiros com melhor conformação e superior estado de engorduramento, podendo resultar em melhores oportunidades de comercialização e de preços pagos ao produtor.

\section{AGRADECIMENTOS}

Os autores agradecem ao Conselho Nacional de Desenvolvimento Científico e Tecnológico (CNPq), pelo suporte financeiro do projeto de pesquisa, e à Coordenação de Aperfeiçoamento Pessoal de Nível Superior, pela bolsa de estudos do primeiro autor.

\section{COMITÊ DE ÉTICA E BIOSSEGURANÇA}

Todos os procedimentos envolvendo os animais utilizados neste estudo foram realizados de acordo com as normas estabelecidas pela Comissão de Ética no Uso de Animais do Setor de Ciências Agrárias da Universidade Federal do Paraná (Protocolo 007/2006).

\section{REFERÊNCIAS}

BROCHIER, M.A.; CARVALHO, S. Efeito de diferentes proporções de resíduo úmido de cervejaria sobre as características da carcaça de cordeiros terminados em confinamento. Arquivo Brasileiro de Medicina Veterinária e Zootecnia, v.61, n.1, p.190-195, 2009. Disponível em: <http://www.scielo.br/ pdf/abmvz/v61n1/v61n1a27.pdf $>$. Acesso em: 3 mar. 2010. doi: 10.1590/S0102-09352009000100027.

BARROS, C.S. Análise econômica de sistemas de produção de ovinos. 2008. 145f. Dissertação (Mestrado em Ciências Veterinárias) - Curso de Pós-graduação em Ciências Veterinárias, Universidade Federal do Paraná, PR.

BORTON, R.J. et al. Comparison of characteristics of lambs fed concentrate or grazed on ryegrass to traditional or heavy slaughter weights. I. Production, carcass, and organoleptic characteristics. Journal of Animal Science, v.83, p.13451342, 2005. Disponível em: <http://jas.fass.org/cgi/content/ full/83/3/679>. Acesso em: 23 maio, 2009.

BUENO, M.S. et al. Características de carcaça de cordeiros Suffolk abatidos em diferentes idades. Revista Brasileira de Zootecnia, v.29, n.6, p.1803-1810, 2000. Disponível em: $<$ http://www.scielo.br/pdf/rbz/v29n6/5712.pdf>. Acesso em: 15 abr. 2009. doi: 10.1590/S1516-35982000000600029.

CARVALHO, P.C.F. et al. Sheep performance in Italian ryegrass swards at contrasting sward heights. In: INTERNATIONAL GRASSLAND CONGRESS, 19, 2001, Piracicaba. Anais... Piracicaba: Unesp, 2001. p.845-846.

CARVALHO, S. et al. Avaliação da suplementação concentrada em pastagem de Tifton-85 sobre os componentes não carcaça de cordeiro. Ciência Rural, v.35, n.2, p.435-439, 2005. Disponível em: <http://www.scielo.br/pdf/cr/v35n2/ a30v35n2.pdf>. Acesso em: 18 jan. 2011.

CARVALHO, S. et al. Desempenho e características da carcaça de cordeiros mantidos em pastagem de tifton-85 e suplementados com diferentes níveis de concentrado. Revista Brasileira Agrociência, v.12, n.3, p.357-361, 2006. Disponível em: <http://www.ufpel.tche.br/faem/agrociencia/v12n3/ artigo17.pdf $>$. Acesso em: 15 abr. 2009. 
CARVALHO, S. et al. Ganho de peso, características da carcaça e componentes não-carcaça de cordeiros da raça Texel terminados em diferentes sistemas alimentares. Ciência Rural, v.37, n.3, p.821-827, 2007. Disponível em: <http:// www.scielo.br/pdf/cr/v37n3/a34v37n3.pdf>. Acesso em: 18 maio, 2011

DANTAS, A. et al. Características da carcaça de ovinos Santa Inês terminados em pastejo e submetidos a diferentes níveis de suplementação. Ciência e Agrotecnologia. v.32, n.4, p.12801286, 2008.

DROUILLARD, J.S, et al. Growth, body composition, and visceral organ mass and metabolism in lambs during and after metabolizable protein or net energy restrictions. Journal Animal Science, v.69, p.3357-3375, 1991. Disponível em: <http://www.scielo.br/scielo.php?script=sci_arttext\&pid=S010384782007000300034>. Acesso em: 20 nov. 2009. doi: 10.1590/ S0103-84782007000300034.

FERREIRA, M.A. et al. Características das carcaças, biometria do trato gastrintestinal, tamanho dos órgãos internos e conteúdo gastrintestinal de bovinos F1 Simental x Nelore alimentados com dietas contendo vários níveis de concentrado. Revista Brasileira de Zootecnia, v.29, n.4, p.1174-1182, 2000. Disponível em: <http://jas.fass.org/cgi/reprint/69/8/3357>. Acesso em: 20 nov. 2009.

GARCIA, C.A. et al. Medidas objetivas e composição tecidual da carcaça de cordeiros alimentados com diferentes níveis de energia em creep feeding. Revista Brasileira de Zootecnia, v.32, n.6, p.1380-1390, 2003.

GESUALDI JR., A. et al. Níveis de concentrado na dieta de novilhos F1 Limousin x Nelore: peso dos órgãos internos e trato digestivo. Revista Brasileira de Zootecnia, v.30, n.6, p.1866-1871, 2001.

HOMEM JR, A.C. et al. Grãos de girassol ou gordura protegida em dietas com alto concentrado e ganho compensatório de cordeiros em confinamento. Revista Brasileira de Zootecnia, v.39, n.3, p.563-571, 2010. Disponível em: <http://www.scielo.br/ scielo.php?pid=S1516-35982010000300016\&script=sci_arttext $>$. Acesso em: 17 abr. 2011

LANDIM A.V. et al. Características quantitativas da carcaça medidas morfométricas e suas correlações em diferentes genótipos de ovinos. Ciência Animal Brasileira, v.8, n.4, p.665-676, 2007. Disponível em: <http://www.revistas.ufg.br/ index.php/vet/article/view/2687>. Acesso em: 07 out. 2011.

MEDEIROS, G.R et al. Efeito dos níveis de concentrado sobre os componentes não-carcaça de ovinos Morada Nova em confinamento. Revista Brasileira de Zootecnia, v.37, n.6, p.1063-1071, 2008.

MOTT, G.O.; LUCAS, H.L. The design, conduct and interpretation of grazing trials on cultivated and improved pastures. In: INTERNATIONAL GRASSLAND CONGREES, 6., 1952, State College. Proceedings... State College: Pensylvania State College, 1952. p.1380-1385.

NRC. NATIONAL RESEARCH COUNCIL. Nutrient requirements of sheep. Washington: National Academy, 1985. 242p

OSÓRIO, J.C.S.; OSÓRIO, M.T.M. Produção de carne ovina: técnica de avaliação in vivo e na carcaça. Pelotas: Universidade Federal de Pelotas, 2003. 73p.

SAEG. Sistema para análises estatísticas e genéticas, versão 9.1. Viçosa: Fundação Arthur Bernardes, UFV, 2007. Online. Disponível em: <http://www.ufv.br/saeg/download.htm>. Acesso em 11 de março de 2010.

SOUZA, R.A. et al. Desempenho produtivo e parâmetros de carcaça de cordeiros mantidos em pastos irrigados e suplementados com doses crescentes de concentrado. Acta Scientiarum: Animal Sciences, v.32, n.3, p.323-329, 2010. Disponível em: <http://www.scielo.br/scielo.php?pid=S0100204X2005001100011\&script $=$ sci_arttext $>$. Acesso: 18 set. 2009. doi: 10.1590/S0100-204X2005001100011.

WHETSELL, M.S. et al. Influence of mass of ruminal contents on voluntary intake and digesta passage in steers fed a forage and a concentrate diet. Journal of Animal Science, v. 82, n. 6, p. 1806-1817, 2004. Disponível em: <http://jas.fass.org/cgi/ content/full/82/6/1806>. Acesso: 20 nov. 2009.

YANEZ, E.A. et al. Utilização de medidas biométricas para predizer características da carcaça de cabritos Saanen. Revista Brasileira de Zootecnia, v. 33, n. 6, p. 1564-1572, 2004. Disponível em: http://www.scielo.br/scielo.php?pid=S151635982004000600024\&script=sci_arttext. Acesso: 15 set. 2009. doi: 10.1590/S1516-35982004000600024. 